\title{
A FORMAÇÃO DOCENTE EM SOCIOLOGIA NO CAP-UERJ: UMA EXPERIÊNCIA ENTRE O ENSINO CURRICULAR E A EXTENSÃO UNIVERSITÁRIA
}

\section{TRAINING OF SOCIOLOGY TEACHERS AT CAP-UERJ: AN EXPERIENCE BETWEEN CURRICULAR EDUCATION AND UNIVERSITY EXTENSION}

\author{
FERREIRA, Walace ${ }^{1}$ \\ PAIN, Rodrigo de Souza ${ }^{2}$ \\ SILVA, Afrânio de Oliveira ${ }^{3}$ \\ SOUZA, Guilherme Nogueira de ${ }^{4}$
}

\begin{abstract}
Resumo
O presente artigo tem como objetivo apresentar o trabalho realizado na formação de professores de Sociologia da Universidade do Estado do Rio de Janeiro (UERJ), a partir da inserção dos autores no quadro docente do Instituto de Aplicação Fernando Rodrigues da Silveira (CAp-UERJ). Nessa direção, apontamos o papel do Laboratório de Ensino, Pesquisa e Extensão em Ciências Sociais (LEPECS), criado em 2017, no que tange à licenciatura em Ciências Sociais da UERJ e de dois projetos de extensão que o acompanham: o projeto "Cinema, curta-metragem e o ensino de Sociologia na educação básica" e o projeto "Sociologia, Juventude e Cidadania". Demonstramos que as atividades desenvolvidas pela equipe de Sociologia do CAp-UERJ constituem-se num importante esforço de experimentação e de desenvolvimento da prática do magistério, de modo que suas especificidades e dificuldades solidificam a formação do licenciando e fortalecem o engajamento por uma educação democrática e emancipatória.
\end{abstract}

PaLAVRAS-CHAVE: Formação docente; Sociologia; CAp-UERJ; Licenciatura; Projetos de extensão.

\footnotetext{
${ }^{1}$ Universidade do Estado do Rio de Janeiro (UERJ) / Instituto de Aplicação Fernando Rodrigues da Silveira (CAp-UERJ). Rio de Janeiro, RJ, Brasil. ORCID: https://orcid.org/0000-0002-7496-9485, e-mail: walaceuerj@yahoo.com.br

2 Universidade do Estado do Rio de Janeiro (UERJ) / Instituto de Aplicação Fernando Rodrigues da Silveira (CAp-UERJ). Rio de Janeiro, RJ, Brasil. ORCID: https://orcid.org/0000-0003-2223-5110, e-mail: rodrigo.pain@gmail.com

3 Universidade do Estado do Rio de Janeiro (UERJ) / Instituto de Aplicação Fernando Rodrigues da Silveira (CAp-UERJ). Colégio Pedro II. Rio de Janeiro, RJ, Brasil. ORCID: https://orcid.org/0000-00031750-825X, e-mail: afranioliveiras@gmail.com

${ }^{4}$ Universidade do Estado do Rio de Janeiro (UERJ) / Instituto de Aplicação Fernando Rodrigues da Silveira (CAp-UERJ). Rio de Janeiro, RJ, Brasil. ORCID: https://orcid.org/0000-0002-0574-7782, e-mail: guilherme.nogueira.souza@hotmail.com
} 
DOI: $10.12957 / \mathrm{e}-\mathrm{mosaicos} .2020 .50389$

\section{ABSTRACT}

This article aims to present the work carried out in the Sociology teachers training programme at the State University of Rio de Janeiro (UERJ) from the authors' insertion in the teaching staff of the Fernando Rodrigues da Silveira Application Institute (CAp-UERJ). In this direction, we point out the role of the Teaching and Research Laboratory in Social Sciences (LEPCS), created in 2017, with regard to the degree in Social Sciences at UERJ and two extension projects that accompany it: the project "Cinema and short-footage and the teaching of Sociology in education "and the project" Sociology, Youth and Citizenship ". We demonstrate that the activities developed by the Sociology team of CAp-UERJ constitute an important effort to experiment and develop the practice of teaching, so that its specificities and difficulties solidify the training of the graduate and strengthen the engagement for a democratic and emancipatory education.

KEYwORDS: Teacher training; Sociology; CAp-UERJ; Graduation; Extension projects.

\section{INTRODUÇÃO}

Dentre os muitos desafios que se apresentam à formação docente, encontra-se o estabelecimento de políticas de acolhimento e de atenção aos estudantes, uma vez que muitos sentem-se deslocados no processo de desenvolvimento de sua formação profissional. São diversos os dilemas que marcam os futuros professores, especialmente os docentes de Sociologia, haja vista as incertezas frente às reformas educacionais empreendidas pelo Estado nos últimos anos. Os desafios de uma formação complexa aliados à falta de prestígio social da profissão têm caracterizado um período de esvaziamento dos cursos de licenciatura, o que gera para os centros formadores desafios ímpares no oferecimento da formação, assim como na produção de condições à permanência e ao engajamento dos estudantes nas práticas formativas de qualidade.

É diante desse contexto que apresentamos, neste artigo, o trabalho realizado na formação de professores de Sociologia da Universidade do Estado do Rio de Janeiro (UERJ), a partir da contribuição do Instituto de Aplicação Fernando Rodrigues da Silveira (CAp-UERJ). O CAp-UERJ é parte integrante do currículo da licenciatura desta universidade, não somente como campo de estágio, mas também de formação teóricometodológica dos licenciandos. Nesta direção, apontamos o papel formativo em Ciências Sociais do Laboratório de Ensino, Pesquisa e Extensão em Ciências Sociais (LEPECS) e de dois projetos de extensão que o acompanham.

O LEPECS/CAp-UERJ, criado em 20175, é um espaço de debates e de experiência docente no qual atividades acadêmicas são desenvolvidas para e com os licenciandos, além de professores da rede estadual e estudantes da educação básica

\footnotetext{
${ }^{5}$ Embora desde 2017 o laboratório tenha sido cadastrado como projeto de extensão na UERJ, e considerando que a vocação extensionista sempre tenha estado em suas ações, apenas em 2020 o termo "extensão" foi formalmente incorporado ao nome, substituindo o anterior Laboratório de Ensino e Pesquisa em Ciências Sociais (LEPCS/CAp-UERJ).
} 
DOI: $10.12957 / \mathrm{e}-\mathrm{mosaicos} .2020 .50389$

do CAp-UERJ. Sob seu guarda-chuva, encontram-se dois projetos extensionistas direcionados para a formação docente, os quais também serão abordados: o projeto "Cinema, curta-metragem e o ensino de Sociologia na educação básica", que vem, desde 2019, destacando o suporte audiovisual como lastro para discussões sociológicas em escolas da rede estadual do Rio de Janeiro; e o projeto "Sociologia, Juventude e Cidadania", que vem, desde 2018, realizando, também em escolas estaduais, palestras, oficinas e rodas de conversa sobre temáticas sociais sensíveis ao público jovem, como combates às formas de discriminação e de bullying, enfrentamento das fake news, valorização dos direitos humanos, atenção ao meio ambiente e divulgação da política de reserva de vagas da UERJ para estudantes de origem popular.

Tendo em vista os objetivos elencados, o presente artigo está dividido em dois eixos temáticos. No primeiro eixo, composto das partes 1 e 2, discutimos a estruturação do CAp e sua função no interior da UERJ como espaço de formação ampla, da educação básica à pós-graduação, passando pela inserção nos cursos de licenciatura da universidade. No segundo eixo, que está dividido em três seções composto da parte 3 e seus subitens 3.1 e 3.2, discutimos o papel do LEPECS e de seus projetos de extensão, na ampliação das possibilidades de formação dos futuros docentes de Sociologia na interface entre ensino, pesquisa e extensão.

\section{O CAP-UERJ COMO ESPAÇO DE ENSINO E FORMAÇÃO}

O CAp-UERJ é uma instituição pública, vinculada à Universidade do Estado do Rio de Janeiro (UERJ), que tem por objetivo desenvolver a formação inicial e continuada de docentes. Criado no ano 1957, em função do Decreto-Lei 9053/1946 que tornou obrigatório às Faculdades de Filosofia, Ciências e Letras o estabelecimento dos chamados "ginásios experimentais", "colégios de demonstração" ou "colégios de aplicação" (CORREIA, 2017) -, o Ginásio de Aplicação da Faculdade de Filosofia, Ciências e Letras, pertencente a então Universidade do Distrito Federal (UDF), nasceu sob a perspectiva de ofertar uma formação docente caracterizada metodologicamente pela articulação entre teoria e prática. Essa perspectiva está alinhada ao pragmatismo do reformador educacional estadunidense John Dewey, e aos pressupostos políticos e teóricos do movimento Escola Nova (FRANGELLA, 2000). Apenas anos depois, em homenagem ao seu primeiro diretor e fundador, após a implantação dos cursos científico e clássico (equivalentes ao ensino médio atual), a escola passou a se denominar Colégio de Aplicação Fernando Rodrigues da Silveira (UERJ, 2013). Em 1997, o CAp propôs sua transformação de Colégio de Aplicação em Instituto de Aplicação, definindo suas características acadêmicas e estabelecendo como local efetivo de experimentação metodológica e de estágio para toda a universidade, reiterando sua condição de unidade acadêmica (MOREIRA; LINS, 2016).

Cabe frisar que, diferentemente do que ocorreu com parte significativa dos ginásios experimentais, a partir da reforma universitária de 1968, o CAp-UERJ manteve-se como parte integrante da formação de futuros professores em diferentes 
arranjos institucionais, não somente como campo obrigatório de estágio, mas também por meio da inserção de seus professores nas disciplinas teóricas e práticas de formação docente em parceira com a Faculdade de Educação e com diferentes institutos da universidade. Esse processo viria a se consolidar, em 2005, com a reforma curricular nas licenciaturas empreendida pela UERJ, que tornou o CAp parte integrante de todas as grades curriculares dos cursos de licenciatura da instituição, com exceção dos cursos de licenciatura localizados fora da cidade do Rio de Janeiro.

Hoje, o CAp-UERJ, localizado no bairro do Rio Comprido, atende a, aproximadamente, mil alunos do ensino fundamental e do ensino médio, além de atender aos licenciandos semestralmente. Segundo o DataUERJ 20196, o CAp atendeu em 2018 a 2.161 licenciandos em disciplinas de estágio supervisionado, disciplinas teóricas e de prática de ensino, oriundos de doze cursos de licenciaturas de diferentes institutos e centros setoriais da universidade. A unidade também conta com inserção na pós-graduação por meio do Programa de Pós-Graduação de Ensino em Educação Básica (PPGEB) e de cursos de especialização direcionados à formação continuada de docentes.

Dessa maneira, o CAp-UERJ busca, desde os seus primórdios, a interface entre a formação básica e a superior. Uma escola no seio da UERJ com espaço de experimentação de novas práticas pedagógicas ancoradas em produção acadêmica desenvolvida por professores-pesquisadores lotados na própria unidade. Assim como nos aponta Correia (2017), esta inserção particular de uma escola no interior de uma universidade é marcada por tensões, especialmente no que tange ao estabelecimento de uma identidade institucional. Entretanto, também é uma inserção potente para o desenvolvimento da formação discente em diferentes níveis, não somente no ensino, mas também na extensão. $E$, nesta perspectiva, as potencialidades de trabalho com as escolas da rede pública e com outros profissionais de ensino são múltiplas, a exemplo das que temos desenvolvido por intermédio do LEPECS e de seus projetos de extensão.

Conforme salientado por Ferreira e Rodrigues (2014), os estudantes da educação básica do CAp-UERJ são oriundos de diversos bairros e de famílias com diferentes condições socioeconômicas. Importante registrar as mudanças na política de acesso empreendidas à unidade pela Lei 6434/20137, a qual estabeleceu uma redução do percentual de vagas reservadas aos filhos de servidores da universidade, de $50 \%$ para $25 \%$, e também estabeleceu a reserva de $40 \%$ das vagas para estudantes carentes negros e indígenas e/ou oriundos integralmente do ensino fundamental público. O percentual restante está reservado à ampla concorrência. A primeira turma sob a nova legislação matriculou-se em 2014. Assim sendo, enquanto unidade educacional, pode-se depreender que o CAp-UERJ se encontra em um processo de alteração de perfil do público atendido. Um movimento mais perceptível

\footnotetext{
${ }^{6}$ Disponível em http://www2.datauerj.uerj.br/pdf/DATAUERJ_2019.pdf Acesso em: 07 abr. 2020.

${ }^{7}$ Disponível em:

http://alerjln1.alerj.rj.gov.br/CONTLEI.NSF/f25571cac4a61011032564fe0052c89c/087bb8cd053320fc8 3257b4f0066f6f1?OpenDocument Acesso em: 07 abr. 2020.
} 
em algumas séries do que em outras, uma vez que, por regra, a entrada de estudantes no CAp se dá no $1^{\circ}$ e $6^{\circ}$ anos do ensino fundamental, por sorteio simples e por prova seguida de sorteio, respectivamente. No entanto, esse ainda é um processo carente de análises mais sofisticadas no que se refere ao desenvolvimento e a permanência destes estudantes na unidade escolar.

Seguindo a lógica dos demais institutos da universidade, o CAp está estruturado em cinco departamentos interdisciplinares. No interior destes, encontram-se as coordenações pedagógicas das disciplinas da educação básica, também responsáveis pelas disciplinas das áreas afins na licenciatura. No caso da Coordenação de Sociologia, tem-se cinco professores, responsáveis pelos dois tempos semanais da disciplina nos três anos do ensino médio, sendo 4 turmas de $1^{\circ}$ ano, 4 turmas de $2^{\circ}$ ano e 3 turmas de $3^{\circ}$ ano. Essa equipe ainda é responsável por ministrar parte das disciplinas de licenciatura do curso de Ciências Sociais, especialmente as 4 disciplinas de estágio supervisionado e as 3 disciplinas de prática pedagógica.

\section{O CURRÍcULO de SOCIOLOGIA NO CAP-UERJ E A FORMAÇÃo DOCENTE}

A prática do magistério tem na experiência um componente fundamental. $O$ curso de licenciatura em Ciências Sociais da UERJ reflete esta perspectiva de modo que o CAp-UERJ se constitui em um espaço de experimentação e de reflexão constantes. Dessa maneira, temos criado possibilidades para que nossos estagiários atuem também como pesquisadores, entendendo que o exercício da investigação é mister para o desenvolvimento da atividade docente.

O que o professor de Sociologia deve buscar, ao realizar seu trabalho com o estudante do ensino médio, é a conquista da imaginação sociológica, como definido pelo sociólogo norte-americano Wright Mills. Ou seja, a preocupação do docente de Sociologia deve consistir em desenvolver em seus alunos a capacidade de ver a realidade em que vivem numa perspectiva que transcenda ao senso comum. É entender as transformações pelas quais passa a sociedade, e auxiliá-los a desenvolverem a razão, a fim de perceberem com lucidez o que está ocorrendo no mundo, e a relação desses acontecimentos com suas próprias vidas (MILLS, 1982). E, com este telos, o currículo de Sociologia do CAp-UERJ é debatido constantemente entre os docentes da Instituição, propondo-se a construir, em colaboração, uma escola democrática e libertadora, pois tal prática é capaz de tornar a educação mais humana e transformadora para que homens e mulheres compreendam que são sujeitos da própria história (FREIRE, 1967).

Assim sendo, trabalhamos para que nossos discentes, tanto os alunos da educação básica quanto os licenciandos inseridos como estagiários nas turmas, busquem a transformação individual e social através da compreensão sociológica do mundo e da educação comprometida com valores republicanos e com a defesa de uma agenda integral de direitos humanos. Dessa forma, buscamos fugir da centralidade do pensamento social de origem europeia, trazendo para o processo de formação, autores e temas que dialoguem numa perspectiva decolonial de sociedade e de educação. 
DOI: $10.12957 / \mathrm{e}-\mathrm{mosaicos} .2020 .50389$

Segundo Legramandi e Gomes (2019):

A formação inicial do professor, do ponto de vista tradicional, é uma formação que visa reproduzir e perpetuar o monoculturalismo, a despersonalização, o aculturamento e que enxerga a diversidade cultural como entrave ao processo educacional. O que se pretende é que o professor monocultural dê lugar ao professor multi e intercultural, transcendendo o etnocentrismo. Este poderá ser aquele que adota uma pedagogia intercultural como instrumento decolonial (LEGRAMANDI; GOMES, 2019, p. 28).

As concepções teórica e curricular que estrutura o ensino e a aprendizagem visam a um caminho duplo. Por um lado, pretende-se uma formação complexa e sólida do ponto de vista da produção de um olhar sociológico sobre o mundo por parte dos estudantes da educação básica, uma formação comprometida com a multiculturalidade, tendo o relativismo cultural como método de compreensão do mundo, e com um projeto decolonial de currículo. Por outro lado, a proposição curricular não está apenas voltada aos estudantes de ensino médio. É parte integrante do processo de formação ampla que os estágios supervisionados fornecem aos licenciandos uma vez que possibilita a rica oportunidade de terem uma formação teórica e prática com o mesmo docente. Esse modelo, no qual o professor das disciplinas de Prática Pedagógica e/ou Estágio Supervisionado também está atuando nas turmas de educação básica, possibilita uma experiência de formação mais integral a despeito dos limites e dos desafios que se colocam para qualquer modelo de formação de futuros professores.

Como aponta Zan (2011), muito dos debates que marcaram a estruturação dos sistemas de ensino estiveram assentados, desde os anos 1930, na dicotomia teoria e prática. A criação, consolidação e massificação dos sistemas públicos de ensino colocaram para as universidades o desafio de formar um número maior de docentes capazes de atuarem em diferentes realidades sociais, atendendo a perfis distintos de alunos, e não somente aos filhos das elites sociais e econômicas. Este era um debate que já estava presente dentre os reformadores da Escola Nova e que se atualiza como debate contemporâneo. Apesar dos limites de todo modelo de formação, a relação intrínseca entre a educação básica e a licenciatura no CAp-UERJ possibilita ensaiar uma alternativa aos desafios de formação docente articulando teoria e prática.

\section{O LEPECS NA FORMAÇÃO PARALELA E CONTINUADA DOS LICENCIANDOS}

Como parte do dinâmico movimento entre teoria e prática, e reconhecendo os limites dos modelos curriculares que engessam os temas e os conteúdos no seio da universidade, a formação paralela e continuada é uma estratégia necessária para ampliar a formação dos licenciandos para exercício futuro da docência. Nessa direção, em 2017, foi criado o Laboratório de Ensino e Pesquisa em Ciências Sociais 
DOI: $10.12957 / \mathrm{e}-\mathrm{mosaicos} .2020 .50389$

(LEPCS/CAp-UERJ), vindo a incorporar formalmente em 2020 o termo "extensão" ao seu nome, dando inclusive mais fidedignidade às ações já desempenhadas ${ }^{8}$.

Assim sendo, o LEPECS constitui-se num coletivo voltado para a formação curricular e extracurricular de estudantes de licenciatura em Ciências Sociais, além de contribuir para a formação continuada de professores de Sociologia inseridos na educação básica. É um braço da ação da universidade para além dos seus muros, focado na formação e no aperfeiçoamento de professores do presente e do futuro.

O laboratório tem sido um espaço dinâmico para professores, estudantes e pesquisadores terem acesso a um conjunto amplo de materiais voltados para o ensino de Sociologia. A importância do LEPECS vincula-se à perspectiva de que suas ações potencialmente ampliem a qualidade da formação dos licenciandos em Ciências Sociais, auxiliando, com isso, professores desta área e demais profissionais de educação interessados nas suas atividades.

A Sociologia é portadora de temas tradicionais, ancorados por conceitos e teorias, os quais precisam estar presentes no currículo e, consequentemente, em sala de aula. No entanto, por se tratar de uma ciência humana extremamente sensível a um mundo dinâmico sob a ótica de suas transformações políticas, econômicas e culturais, precisa desenvolver instrumentos de atualização e de releitura do seu objeto, colocando teoria e prática em constante comunicação.

Ao propor a produção e a organização de um conjunto de materiais para a educação básica, assim como a criação de um espaço de pesquisas e debates sobre o ensino de Sociologia e a formação de professores, o laboratório propõe a integração entre ensino e pesquisa, além de se apresentar como destaque numa área do conhecimento ainda em vias de legitimação no estado do Rio de Janeiro e no Brasil, principalmente diante do contexto de reforma do ensino médio.

$\mathrm{Na}$ criação desse espaço amplo de construção pedagógica e de produção acadêmica, também procuramos seguir as Orientações Curriculares Nacionais - OCN's (BRASIL, 2006), que recomendam o uso de ferramentas como a pesquisa, a elaboração de recursos didáticos os mais variados e o contato interdisciplinar. Nesse sentido, o LEPECS se propõe a uma dupla função, fundamental para o processo de ensino-aprendizagem: condensar experiências didático-pedagógicas, direcionando-as para a utilização em sala de aula, assim como pensar a própria realidade na qual estamos inseridos. Como salientado por Araújo (2018), ao tratar da importância dos laboratórios de Ciências Humanas:

No plano geral, os estudos de laboratório assumiram centralidade na explicação dos fatos científicos nas últimas duas décadas. Os laboratórios converteram-se num dos pontos mais instigantes, mas também mais controvertidos do desenvolvimento da abordagem

\footnotetext{
${ }^{8}$ Em 2020, o LEPECS também passou a ser linha de pesquisa do Grupo de Pesquisa em Ciências Sociais e Educação (GPCSE) da UERJ, liderado pela professora Dra. Helena Bomeny e tendo como vice-líder a professora Dra. Raquel Emerique. Foi da professora Raquel, inclusive, a sugestão da incorporação do termo "extensão" ao nome do laboratório.
} 
DOI: $10.12957 / \mathrm{e}-\mathrm{mosaicos} .2020 .50389$

sociológica do problema do conhecimento. É indiscutível, hoje, o progressivo reconhecimento analítico que as circunstâncias do laboratório não são responsáveis somente pela produção do conhecimento científico, mas também pela configuração do próprio contexto social (ARAÚjO, 2018, p. 69).

Para além do impacto acadêmico e do processo formativo, o contato dos licenciandos com diferentes profissionais da Educação, seja como palestrantes, seja como participantes de mesas e atividades, auxilia na construção de uma percepção adequada da carreira docente e dos desafios nela presentes. Trata-se de uma visão apontada para as vantagens e desvantagens que as condições reais de inserção e vivência nas diferentes redes educacionais, públicas ou privadas, estaduais ou federais, possibilitam. $\mathrm{O}$ fato de o estudante de licenciatura transcender sua limitada experiência de estágio na formação inicial para se tornar interlocutor de docentes inseridos em distintas instituições, com diferentes percursos de formação, amplia as possibilidades de êxito deste futuro docente quando levado à complexa e desigual realidade escolar brasileira.

Como parte da estratégia de formação dos licenciandos e de parceria com professores que já atuam no ensino de Sociologia, o LEPECS desenvolve dois projetos de extensão, os quais serão tratados nas seções seguintes.

\section{Projeto "Cinema, Curta-metragem e o ensino de Sociologia na educação básica"}

Este projeto vem desde 2019 destacando o suporte audiovisual como lastro para discussões sociológicas, valorizando e reconhecendo a importância do filme como recurso didático. Segue-se o entendimento de Martins (2007), segundo o qual a obra cinematográfica é um constructo sobre o real que articula distintas formas de expressão e comunicação humanas. Para o autor,

O filme não é reflexo do real, tampouco traduz a verdade dos fatos. Fruto de um imaginário (autor) que adquire determinada forma e que age sobre outros imaginários (espectador) o filme é um artefato que demanda análise interna e do contexto que o cerca cujos aspectos a serem selecionados é dado pelas questões de quem analisa. (MARTINS, 2007, p. 3).

Diante desta perspectiva, entendendo os limites da obra fílmica, seja ela documental ou ficcional, pretende-se superar algumas lacunas no cotidiano das escolas da rede pública, possibilitando um diálogo acadêmico entre universidade e educação básica. Tendo como fonte de inspiração os antigos cineclubes, verifica-se a ideia de utilizar a exibição de filmes e sua discussão como opção pedagógica e cultural para os alunos de licenciatura em Ciências Sociais em sua interface com professores da rede pública estadual. 
DOI: $10.12957 / \mathrm{e}-\mathrm{mosaicos} .2020 .50389$

Reconhecendo-se que o mundo atual é dominado por imagens e que a principal fonte de conhecimento da contemporaneidade é o meio audiovisual, especialmente com a virtualização da vida e a formação de uma inteligência coletiva, como aponta Pierre Levy (1998), temos como proposta desenvolver procedimentos teóricos e metodológicos ao uso do cinema como recurso didático em sala de aula e estimular os licenciandos de Ciências Sociais a usar este instrumento no debate de temas sociológicos.

Tendo por suporte o imenso acervo de filmes etnográficos existentes no Núcleo de Antropologia e Imagem (NAI) da UERJ, pretende-se socializar o seu uso por meio de uma proposta de dinamização que integre melhor a universidade e a rede pública estadual, o ensino de licenciatura e o ensino básico. Ademais, incorpora-se o uso de filmes e curtas disponíveis na internet, especialmente no portal "Porta Curtas", tendo em vista a maior disponibilidade deste material para professores que não possuem acesso ao acervo do NAI.

Com o desenvolvimento do projeto, esperamos ampliar a formação dos alunos e, sobretudo, a formação continuada de professores para que se sintam estimulados a repensar as imagens e as representações sociais do seu universo, bem como o papel e o significado da universidade, do professor, do aluno e da prática docente na contemporaneidade. A ideia é criar uma ponte entre os saberes das disciplinas básicas das Ciências Sociais e o universo dos estudantes já habituados com a linguagem do cinema.

Apesar do uso de recursos audiovisuais não ser novidade na prática docente, a presença de universitários e a troca com estudantes secundaristas e professores da rede pública estadual trouxeram o componente metodológico de novidade. 0 fundamental é ter em mente que o material a ser exibido deve ter relação com o conteúdo estudado ou a ser trabalhado. Com isso, é importante refletir sobre o público que se pretende alcançar e quais materiais são mais adequados aos objetivos elencados nos planejamentos das aulas, levando em consideração o perfil do público atendido.

Em 2019, foram visitadas, como realização de atividades, quatro escolas estaduais em diferentes pontos do estado do Rio de Janeiro: Colégio Hélio Rangel (Duque de Caxias), Colégio André Maurois (Gávea), Colégio Maria Nazareth Cavalcanti Silva (Cascadura) e Colégio Cláudio Coutinho (Belford Roxo). Pretendemos, com essas ações, contribuir para a superação de algumas ausências no cotidiano das escolas da rede pública por intermédio de um diálogo acadêmico e orgânico entre a universidade e a educação básica em um processo dialógico para a construção de conhecimento. Dessa maneira, temos desenvolvido discussões relevantes e atualizadas sobre os diversos temas abordados, refletindo no sucesso do projeto que já começa a contar com novos parceiros, professores da rede estadual de educação, interessados em levar a proposta para suas escolas em 2020 , perspectiva adiada por conta da pandemia do novo coronavírus. 
DOI: $10.12957 / \mathrm{e}-\mathrm{mosaicos} .2020 .50389$

A devolutiva dos estudantes das escolas parceiras tem sido bastante satisfatória, não somente pela forma como a experiência audiovisual é incorporada, mas também pela presença dos licenciandos, jovens universitários, muitos deles oriundos também de escolas públicas da rede estadual. O impacto simbólico da presença dos estagiários, muitos negros e de bairros empobrecidos da cidade, ainda carece de uma análise sistemática, mas a experiência tem apontado para uma profunda identificação por parte dos estudantes das escolas parceiras e, ao mesmo tempo, um estranhamento que eventualmente produz reflexão sobre as perspectivas de futuro. Esta percepção está baseada nos depoimentos feitos pelos estudantes da educação básica e nos relatos de diálogos que estes estudantes estabelecem com os licenciandos, sujeitos ativos dessa mediação/parceria com o professor da rede estadual de educação.

A presença dos estagiários e suas vivências numa universidade pública têm sido caminho indutor, inclusive, da ampliação do interesse de estudantes de ensino médio periféricos pela universidade e, especialmente pela UERJ. Assim como tem sido estratégico para a divulgação das políticas de reserva de vagas para estudantes carentes negros e/ou procedentes dos sistemas públicos de educação, direito frequentemente desconhecido pela maioria dos estudantes das escolas estaduais visitadas até o momento.

\section{Projeto "Sociologia, Juventude e Cidadania"}

Funcionando desde fins de $2017^{9}$, o nosso segundo projeto caracteriza-se por levar discussões relacionadas ao currículo de Sociologia a colégios da rede pública estadual do estado do Rio de Janeiro, objetivando contribuir, majoritariamente, junto à juventude, para a ampliação do debate sobre temáticas importantes para o desenvolvimento da cidadania. Para tal, temos buscado parcerias internas no âmbito da UERJ, com profissionais de diversas áreas, contribuindo interdisciplinarmente; e parcerias externas, com professores e profissionais de instituições as mais diversas e que também estejam interessados nesse tipo de reflexão/formação junto ao público jovem. No começo, o projeto tinha como membros professores de Sociologia do ensino superior e da educação básica. Aos poucos, contudo, temos incorporado psicólogos e estudantes de Psicologia, que têm ajudado nas conversas de enfrentamento às discriminações cotidianas, dentre as quais se encontram o bullying. Também temos organizado discussões para auxiliar o enfrentamento da depressão na juventude.

Como nos ensinou Paulo Freire (1989, p.13), "a leitura do mundo precede sempre a leitura da palavra e a leitura desta implica a continuidade da leitura daquele". Por isso, é fundamental que os conceitos abordados façam sentido para o mundo do estudante e que ele possa utilizá-los e potencializá-los em articulação e a partir da sua própria realidade. O letramento conceitual que a Sociologia tem a oferecer deve sair

\footnotetext{
${ }^{9}$ Devido ao calendário escolar, embora o projeto tenha começado em 2017, as primeiras idas aos colégios só se deram em 2018.
} 
DOI: $10.12957 / \mathrm{e}-\mathrm{mosaicos} .2020 .50389$

do encontro fecundado pelas referências da vida dos estudantes, servindo-lhes de insumo para o desenvolvimento de seu senso crítico ao (re) encontrar a realidade.

Esse projeto de extensão parte de uma perspectiva do papel da Sociologia no ensino médio que procura pensar o saber como uma prática que pode ser construída a partir de formas alternativas e complementares de ensino. As iniciativas se pretendem em parceira com as escolas da rede estadual e, em especial, com os docentes que atuam no ensino de Sociologia nestas instituições. Seguindo essa direção, temos estimulado a participação de estudantes de licenciatura em Ciências Sociais da UERJ também junto a esse projeto extensionista, conhecendo, já na formação universitária, a realização de um trabalho que articula universidade e sociedade, teoria e prática, além de levá-los para a realidade das escolas visitadas.

Se, em 2018 os licenciandos vivenciavam as atividades como ouvintes, em 2019, passamos a contar com eles na posição de protagonistas ativos, principalmente nas atividades em que abordamos o sistema de cotas da UERJ e apresentamos as características que dão a essa universidade um caráter plural e popular. Assim, o projeto, tem apoiado a formação do estudante da licenciatura no que tange à observação da Sociologia em múltiplos espaços de realização educacional e de modo diferente da aula tradicional. Ademais, abre-se espaço para a pesquisa que o licenciando poderá realizar a partir dessa vivência, bem como para a produção de artigos baseados em suas experiências.

Algumas vezes participamos em eventos mais amplos organizados pelas instituições escolares. Em 2019, por exemplo destacamos a participação do projeto em duas rodas de conversa realizadas no Colégio Estadual Professora Maria Nazareth Cavalcanti Silva em Cascadura, durante a "Semana de Prevenção à Violência nas Escolas", orientada pela SEEDUC/RJ, e na roda de conversa realizada no Colégio Estadual Professor Clóvis Monteiro em Higienópolis, durante o mesmo evento sugerido pela SEEDUC/RJ nas escolas. Nosso projeto também foi convidado para realizar uma atividade durante a "Semana da Normalista", no Instituto de Educação Governador Roberto Silveira (Duque de Caxias), na qual fizemos uma oficina sobre formas de enfrentamento às discriminações cotidianas, destacando-se os preconceitos raciais e de gênero. Mais uma vez a participação dos licenciandos foi fundamental no compartilhamento de vivências e no apoio às atividades.

Em 2019 realizamos 17 ações entre palestras, oficinas, rodas de conversa e debates, em 9 colégios distintos. Em 2018, já havíamos feito 14 atividades em 12 colégios estaduais do Rio de Janeiro. Até o fim de 2019 foram, portanto, 31 iniciativas. As cidades envolvidas nesses dois anos foram: Rio de Janeiro; Duque de Caxias; Petrópolis; São Gonçalo; Niterói e Paty do Alferes. Considerando, por fim, o trabalho realizado desde 2018, alcançamos ações suficientes para dividirmos nossa atuação em seis áreas temáticas, a saber: 1) Contra discriminação; 2) Combate às Fake News; 3) Gênero, Indústria cultural e Violência doméstica; 4) Cidadania, Política e Direitos Humanos; 5) A importância do meio ambiente e da reciclagem; 6) O sistema de cotas da UERJ e a perspectiva de mobilidade social de jovens de origem popular. 
DOI: $10.12957 / \mathrm{e}-\mathrm{mosaicos} .2020 .50389$

Devido à pandemia em 2020 e a impossibilidade de irmos às unidades escolares, optamos por redirecionar a produção formativa para as redes sociais (Instagram e Facebook). Num primeiro momento, elencamos imagens das ações concretizadas nos anos anteriores. Em momento mais recente, temos produzido postagens de interesse do projeto tendo como público-alvo estudantes da educação básica, licenciandos em Ciências Sociais e professores de Sociologia. Até o começo de outubro realizamos postagens críticas/reflexivas/informativas sobre os seguintes temas: Fake News; Racismo; Cotas universitárias; Cotas na Uerj; Sistema Único de Saúde (SUS) e Ciberbullying.

\section{CONSIDERAÇÕES FINAIS}

Escrever sobre a formação docente implica também em refletir sobre 0 significado do que é ser professor, em especial nesse momento de inquietudes e perplexidades que observamos no atual cenário nacional em termos de políticas de educação.

O processo de se tornar professor ocorre quando se educa, relacionando sua existência com a existência do outro, em um processo dialético de construção humana. Desse jeito, a complexidade de se educar e se tornar educador nos motiva a repensar nossas práticas cotidianamente, forçando-nos a mantermos um diálogo constante tanto entre os docentes quanto entre os discentes, que cada vez mais necessitam de suporte teórico-metodológico para lidar com as mudanças na sociedade. Portanto, as inquietudes do trabalho docente no CAp-UERJ levaram-nos a ampliar os espaços de aprendizagem tanto de alunos da educação básica quanto dos licenciandos, de modo que todos possam ser marcados pela produção de uma postura crítica da vida social, de resgate da cidadania e da defesa da democracia.

Assim, buscamos destacar que o trabalho desenvolvido no âmbito do Laboratório de Ensino, Pesquisa e Extensão em Ciências Sociais (LEPECS) produz tanto efeitos internos, na formação de discentes da educação básica e dos licenciandos, quanto externos, para os profissionais que atuam na educação básica da rede pública do estado do Rio de Janeiro e seus respectivos alunos. Seus efeitos internos podem ser observados na diversidade de metodologias e práticas pedagógicas em sala de aula e na variedade de atividades apresentadas aos licenciados como possibilidades de trabalho docente em relação ao campo real de atuação desses futuros profissionais. No que tange aos efeitos externos pode-se destacar a contribuição da extensão do CAp-UERJ para a comunidade fluminense e para os profissionais que atuam na rede pública.

Os professores que assumem a disciplina de Sociologia na rede estadual não possuem efetiva autonomia, mas frequentemente vivenciam uma docência solitária e marcada pela precarização em função das dinâmicas organizacionais da Secretaria Estadual de Educação (SEEDUC-RJ). A ausência de uma equipe de Sociologia em cada unidade e a necessidade de dividir ou complementar carga horária em diversas escolas, por exemplo, fazem com que o trabalho docente seja realizado sem apoio ou 
DOI: $10.12957 / \mathrm{e}-\mathrm{mosaicos} .2020 .50389$

interlocutores. Somado a isso, sabe-se também que a maioria dos professores que atuam na disciplina de Sociologia não possui formação em Ciências Sociais ou Sociologia, como ocorre em outras áreas presentes na grade curricular da educação básica. Logo, o trabalho desenvolvido pelo LEPECS também possibilita o diálogo, a difusão de experiências e de práticas pedagógicas em sala de aula, possibilitando assim um compartilhamento desse trabalho. $O$ resultado tem sido a necessária ponte entre a universidade e seu Instituto de Aplicação e os professores que atendem na rede estadual.

O processo de formação de professores enfrenta diferentes obstáculos, em especial o de Ciências Sociais, pelas razões já tratadas anteriormente. Entretanto, o trabalho realizado no CAp-UERJ, no âmbito do LEPECS e dos demais projetos de extensão que desenvolvemos, tem demonstrado que uma formação sólida de prática docente não pode prescindir de atividades que extrapolem a sala de aula e os limites da grade curricular, mesmo que esta esteja assentada numa dinâmica relação teoriaprática no seio de um Instituto de Aplicação.

Os licenciandos não são meros expectadores, mas agentes em seu próprio processo de formação de ensino-aprendizagem. São atores na formação de estudantes de ensino médio, seja por meio das aulas que ministram no CAp, seja por intermédio da participação em projetos que incidem sobre a realidade educacional de estudantes da rede estadual de educação. Ainda há muitos desafios para tornar o processo de formação docente mais eficiente e prazeroso para todos os atores envolvidos, mas acreditamos que o caminho trilhado até o momento tem apresentado resultados positivos e atualizados frente ao campo da prática pedagógica e da pesquisa educacional.

\section{REFERÊNCIAS:}

ARAÚJO, Marcelo. Laboratório de Humanidades como espaço de interdisciplinaridade e formação crítica no Ensino Médio. In: BODART, C. (Org.). Sociologia Escolar: ensino, discussões e experiências. 1.ed. Porto Alegre: CirKula, 2018.

BRASIL. Orientações curriculares para o Ensino Médio. Vol. 3 (Parte de Sociologia). Ciências humanas e suas tecnologias/ Secretaria de Educação Básica. Brasília: Ministério da Educação, 2006.

CORREIA, Evelline Soares. Colégios de aplicação pedagógica: sua história e seu papel no contexto educacional brasileiro. Rev. Eletrônica Pesquiseduca, vol. 09, n. 17, p. 116-129. jan-abr.2017.

DATAUERJ 2019: anuário estatístico base de dados 2018. Universidade do Estado do Rio de Janeiro/Núcleo de Informação e Estudos de Conjuntura. Rio de Janeiro: UERJ, 2019.

FERREIRA, Walace; RODRIGUES, Thaiana. Notas acerca de experiências e desafios do estágio docente em Sociologia. In: Anais do IX Simpósio Educação e Sociedade Contemporânea: Desafios e Propostas. CAp-UERJ, Rio de Janeiro, 2014. 
DOI: $10.12957 / \mathrm{e}-\mathrm{mosaicos} .2020 .50389$

FRANGELLA, Rita de Cássia Prazeres. Colégio de Aplicação e a instituição de uma nova lógica de formação de professores: um estudo histórico no Colégio de Aplicação da Universidade do Brasil. In: I Congresso Brasileiro de História da Educação, 2000, Rio de Janeiro. I Congresso Brasileiro de História da Educação. Rio de Janeiro: Gráfica Scortecci, 2000. vol. 1. p. 375-376.

FREIRE, Paulo. $A$ importância do ato de ler: em três artigos que se completam. São Paulo: Autores Associados: Cortez, 1989.

FREIRE, Paulo. Educação como prática da liberdade. 30.ed. Rio de Janeiro: Paz e Terra, [1967], 2007.

LEGRAMANDI, Aline Belle; GOMES, Manuel Tavares. Insurgência e resistência no pensamento freiriano: propostas para uma pedagogia decolonial e uma educação emancipatória. Revista @mbienteeducação. São Paulo: Universidade Cidade de São Paulo, vol. 12, n. 1, p. 24-32, jan/abr, 2019.

LEVY, Pierre. A Revolução contemporânea em matéria de comunicação. Revista FAMECOS, n. 09, Porto Alegre, 1998.

MARTINS, Ana Lucia Lucas. Cinema e ensino de Sociologia: usos de filmes em sala de aula. XIII Congresso Brasileiro de Sociologia, UFPE, Recife, 2007.

MILLS, Charles Wright. A imaginação sociológica. Rio de Janeiro: Zahar, 1982.

MOREIRA, Helena Maria Alves; LINS, Mônica Regina Ferreira. O CAp-UERJ e a educação integral - Reflexões sobre o espaço e tempo escolar. In: X Simpósio educação e sociedade contemporânea: desafios e propostas. Rio de Janeiro, UERJ, 2016.

UERJ. Projeto Político Pedagógico do Instituto de Aplicação Fernando Rodrigues da Silveira (CAp/UERJ). Rio de Janeiro, 2013.

ZAN, Dirce Pacheco. O estágio na formação do professor de Sociologia. Cad. CEDES, Campinas, vol. 31, n. 85, p. 447-458, 2011.

Recebido em 22 de abril de 2020

Aceito em 23 de setembro de 2020

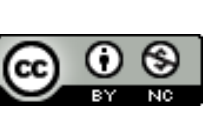

A e-Mosaicos Revista Multidisciplinar de Ensino, Pesquisa, Extensão e Cultura do Instituto de Aplicação Fernando Rodrigues da Silveira (CAp-UERJ) está disponibilizada sob uma Licença Creative Commons - Atribuição-NãoComercial 4.0 Internacional.

Os direitos autorais de todos os trabalhos publicados na revista pertencem ao(s) seu(s) autor(es) e coautor(es), com o direito de primeira publicação cedido à e-Mosaicos.

Os artigos publicados são de acesso público, de uso gratuito, com atribuição de autoria obrigatória, para aplicações de finalidade educacional e não-comercial, de acordo com o modelo de licenciamento Creative Commons adotado pela revista. 